\title{
Thoughts of Sorts
}

\section{Sebastian Oreamuno}

\begin{abstract}
My multi-media daily practice of dancing, drawing, and writing is a generative space that does not buy into the idea and pressure of productivity. It has been over four years since I started this daily practice, which I began on June 2I, 20I7. I engage this practice to process. It is a practice for processing "things" such as texts, theories, daily situations, and our current time, informed by sensations and feelings. What has emergedfor me in this practice is how every aspect of it - the dancing, drawing, writing, music, silence, camera, space, time, cats (yes! my cats sometimes dance with me), and life — plays a role. All of these things are in conversation with one another, and they inform who I am, my becoming. Lately, I have engaged this practiceas a methodology. That is, I have used it to excavate and re-connect with the Chilean national dance, a danceform that I used to practice when I was a child in Chile. However, for me, this practice is much more thanthat. These writing and drawings are from me, about me, and extensions of me - my thoughts of sorts.* And, they are my gifts to you.
\end{abstract}

\section{Keywords}

reflections, refractions, traces, daily practice, art

* The title is inspired by, and taken from, Georges Perec's book of the same name: a collection of essays that explores the everyday. 
April 4, 2020

from the nebulous

the ether

emerges a phantom

a dream only now remembered

only now recognizable

and

that's it

that's the way forward

the path meant to be

taken

or perhaps it was only a déjà vu

nevertheless, the tingling comes

and you proceed

April 8, 2020

I'm reminded of the ocean

that salty liquid that leaves stars on your skin

and a stickiness that is both unbearable and

joyous because you know, I know, I got to swim,

dunk my head, relax, maybe ride a wave

the sun in my eye as I float

the sizzling of my skin as the sun touches me more and more

the smell of coconut - the sunscreen

away, so far away

I'm nostalgic for a time that is many times, for a place that is no place

and all because I danced

in a basement

April 13, 2020

the days seem to disappear before

I can even register them

I am continuously faced with

a lived ephemerality

a lived evanescence

these daily traces are all

that remain

a reminder of what I've

forgotten 
April 22, 2020

$$
\begin{aligned}
& \text { doubling } \\
& \text { involving in time } \\
& \text { the timing couldn't } \\
& \text { be better } \\
& \text { multiplying takes } \\
& \text { time } \\
& \text { double it by } \\
& \text { folding in } \\
& \text { half } \\
& \text { then in half again } \\
& \text { and again and } \\
& \text { again and again } \\
& \text { until you're so } \\
& \text { involved, so folded } \\
& \text { in that you come out } \\
& \text { the other side }
\end{aligned}
$$

doublings are creases

in time, not projections

April 25, 2020

there's always a story to tell

in a kiss

in friction

in a meal

a story,

waiting and wanting

to be heard

May 2, 2020

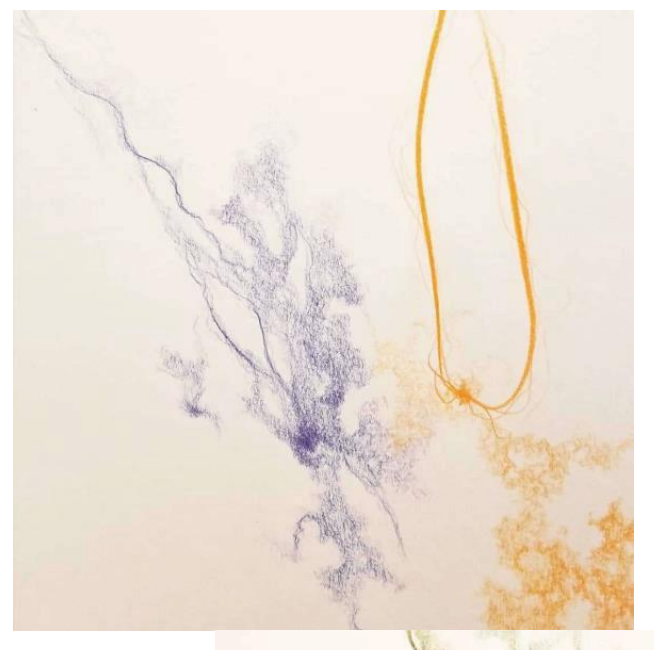

a leafy monster emerges in time the pencil crayons and paper have a pedagogy of their own a pedagogy of patience, layering and allowing for spaces, gaps, in-betweens the leafy monster emerges to teach me about growth and decay, vibrance and rot, cycles and transitions it stares at me in silence I hope I've learned the/my lesson 
May 5, 2020

it was through imagination and sensation that I was able to bear witness from afar

to be there from a distance

I cannot remove or discard what

has been incorporated, what I've read and I don't intend on claiming those as my own

I'm just trying to contend with the mine that's not mine, or the not mine that is now a part of me

May 9, 2020

echoes

ripples

affected

uncertainties lead to

moving

reverberations

choices

all to try and be free

to find the margin of

manoeuverability

but cracks lead to new

spaces/enclosures

follow the breadcrumbs?

feel the ripples

hear the echoes

sense the reverberations

then let them go

let yourself go

be affected and affect

May 14, 2020

the race was never there

the competition didn't exist

I made it all up

we made it all up

perhaps now I can relax

and rest 
May 17, 2020

abeyance...

...to dance the spell of my own creation

holding on to our practices of making time speed up

does not create more time, just momentum

towards a future we don't understand

we believed progress was containable

we believed in progress

and now, we're in a much-needed suspension

May 20, 2020

a changing landscape emerges

or rather a landscape that was already in

transition becomes apparent

when you tune your awareness to the movement

when you turn towards the movement

you can't search for it

you can only sense it and try

to focus on it

don't bother trying to grasp it

because it's ungraspable

fleeting

evanescent

transient

it is and was and will be

always already out of (your) reach

May 31, 2020

suspended and lost

in trajectories

of thoughts unfolding faster

than I can process

a process

of traversing at the speed

of neurons firing

of connections and gaps being made

all I really know is

that I'm processing

and perhaps I don't even know that because my awareness is split

but I can feel the process of processing

I feel suspended and lost 
June 12, 2020

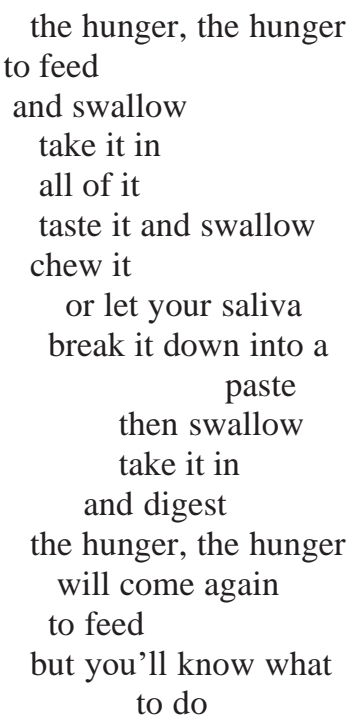

June 16, 2020

finding a way forward

sometimes only requires

remembering the paths

not taken

a different orientation

leaning a different way

June 19, 2020

meet me in the fork in the road

so we can walk down the path together

meet me in the lair below

so we can ride out the tempestuous weather

meet me where the fire-souls go

so we can drift through dreams like a feather

meet me somewhere no one will know

the memory that has us tethered 
June 21, 2020

I can't find the words they're around me buzzing

but I can't seem to focus on them this is this moment and the next might hold something different but for now I'll have to sit in the confusion between numerous trains of thought and find my place in the swirl perhaps it wasn't words or a word I was looking for but a feeling tranquility

July 2, 2020

\section{frames}

the stories they tell aren't the stories they hold stilling movement framing scenarios fantasizing containment the illusion of the frame a window looking out to interpretation things don't stay so neatly packed, packaged, framed the frame breaks and the stories spill

July 23, 2020

this interruption was necessary we needed to do this to keep going ruptures are openings

and if we open together if we open up together then we can go through the rupture, the crack 
we need to make things burst

not ourselves

we need to break things

and pick up the pieces

always create anew with what's there

easier said than done

breaks are necessary

this interruption was necessary

July 24, 2020

succulent, delicious

change can be exquisite

an acquired taste

certainly!

because we seek certainty,

clarity,

move!

stability

explore with movement

experiment with it

taste it

taste movement with your body

you're already doing it anyway

you're just not aware you're doing it

and see where the movement

takes you

August 3, 2020

el canto de la orilla

el cuento de la orilla

is of patience and

transformation

is of persistence and

negotiation

the edge/shore/border

is a song/story

unfolding and

unfinished

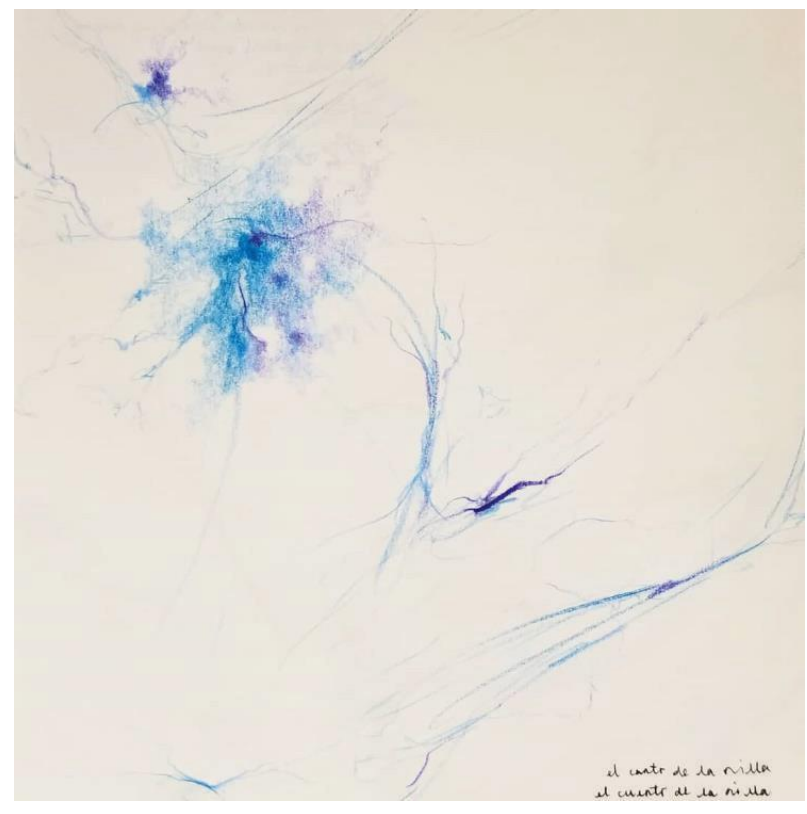




\section{Author biography}

Born in Santiago, Chile, Sebastian Oreamuno is a Toronto-based artist, educator, and researcher whose artistic and academic interests trace the connection between movement and memory, (im)migration and diaspora, the participatory body, popular culture, and multi-media practices. Sebastian holds a BA in Psychology from Simon Fraser University (Vancouver), an MA in Dance from York University (Toronto), and he is currently working on a PhD in Dance Studies at York. His Master's project investigated the relationship between men and pointe work, a practice primarily associated with ballerinas. Sections of this project have been published in Contingent Horizons, Performance Matters, and Dance Collection Danse: The Magazine. His doctoral research explores how movement participates in the summoning of memories, particularly in the context of Chilean migrants in Canada. Sebastian is currently developing Fragmentos, a multi-media project that explores the fragmentation of self through the imposition of assimilation, with documentary filmmaker Juan Pablo Pinto. Sebastian is also a cofounder of Untitled 37, a multidisciplinary arts collective that engages "steeped" practices as a way to question "panic-production." 